\title{
"Science is Everywhere, but No One Knows It": Assessing the Cultural Distance to Science of Rural South African Publics
}

\section{Lars Guenther, Peter Weingart \& Corlia Meyer}

To cite this article: Lars Guenther, Peter Weingart \& Corlia Meyer (2018): "Science is Everywhere, but No One Knows It": Assessing the Cultural Distance to Science of Rural South African Publics, Environmental Communication, DOI: 10.1080/17524032.2018.1455724

To link to this article: https://doi.org/10.1080/17524032.2018.1455724

曲 Published online: 03 May 2018.

Submit your article to this journal $₫$

Џ Article views: 48

View Crossmark data \ulcorner 


\title{
"Science is Everywhere, but No One Knows It": Assessing the Cultural Distance to Science of Rural South African Publics
}

\author{
Lars Guenther (1D), Peter Weingart (D) and Corlia Meyer (D) \\ Centre for Research on Evaluation, Science and Technology (CREST), Stellenbosch University, Stellenbosch, South \\ Africa
}

\begin{abstract}
In science communication, a prerequisite for reaching different parts of a society is to find out how these publics experience and interpret science. Since rural South African publics are perceived to exhibit a large cultural distance to science, the present exploratory study aimed to know in more detail how rural South Africans perceive and understand science in their local and social contexts. Theoretical notions on cultural distance and the methodological approach of segmentation studies were considered. Semi-structured interviews with rural South Africans were carried out in four towns $(n=52)$ that differ with respect to having a large scientific installation in their vicinity, or not. Sensitively comparing local and social contexts helped identifying three different publics who differed regarding their perceptions of science; however, the large scientific installations only made a difference in perceptions for those publics who were generally less exposed to and less knowledgeable about science.
\end{abstract}

\section{ARTICLE HISTORY}

Received 15 November 2017

Accepted 16 March 2018

\section{KEYWORDS}

Public perceptions of science and technology; cultural distance; segmentation study; exploratory analysis; rural publics in South Africa

The statement cited in the title of this article is from a young tourist office employee in a rural town in South Africa; it is the immediate reaction to our explanation of the study we were planning to do. The statement expresses in striking clarity the reality of modernity even in places where it would be expected least: the contemporaneity of a world, which is inexorably permeated with technologies, scientific knowledge, and practices relying on it, and a world of traditional customs, values, and everyday routines in distance to science. Thus, this comment captured the objective of the research we planned to undertake perfectly. In light of recent research findings highlighting that rural publics in South Africa are perceived to be largely removed from science (Guenther \& Weingart, 2018), we wanted to know in more detail how rural South Africans perceive, experience, and understand science in their daily contexts.

In the global public perception of science and technology (S\&T) research literature, rural populations are an under-researched population. While the science engagement framework of South Africa's Department of Science and Technology (DST, 2014) states the need to popularize science, enhance scientific literacy, and to develop a critical and engaging public, most of the proposed strategies focus on the country's urban areas. This is surprising as the former White Paper on Science and Technology (Department of Arts, Culture, Science and Technology, 1996) explicitly highlighted that rural publics, in South Africa, to take part in the country's transition process, need special assistance to adopt innovations and to get access to (scientific) information. More than a third of the South African population lives in rural areas of the country (World Bank, 2015). If science communication is to contribute to the democratic political culture and 
to economic development by raising people's capacity of critical inquiry and reflection, it has to reach out to all segments of the society equally.

For programs, such as South Africa's science engagement framework (DST, 2014), to be effective and to be designed for all segments of the population, it has to address people's actual needs and interests (Fischhoff, 2013). Thus, more has to be known about people's everyday contexts in which they make sense of science (see Michael, 2002; Wynne, 1995). ${ }^{1}$ This implies moving beyond the traditional surveys of public perceptions of S\&T. Hence, the present study will assess how rural South Africans perceive, experience, and understand science, by making use of theoretical considerations of cultural distance (e.g. Raza, Singh, \& Shukla, 2009) and using an exploratory design as well as the methodological approach of segmentations studies (e.g. Hine et al., 2014; Schäfer, Füchslin, Metag, Kristiansen, \& Rauchfleisch, 2018; Slater, 1996).

With respect to the diversity of rural communities, South Africa offers a unique setting. The present study compares publics in two types of typical rural communities: an agricultural (Clanwilliam) and a fishing town (Paternoster) with no obvious connection to any science, as well as two towns that became internationally famous for the large scientific installations in their vicinity: Sutherland (hosting the Southern African Large Telescope (SALT)) and Carnarvon (hosting the Square Kilometre Array (SKA)). ${ }^{2}$ Because of the installations' impact on the communities, science may play a stronger role in people's lives. The distance to science might therefore be smaller than in other towns. If that was true, the findings of the present study may be a prerequisite for designing effective science communication, ${ }^{3}$ and may inform better future policy decisions.

\section{Research into public perceptions of S\&T}

Starting in the 1970s in the United States, public perceptions of S\& $T$ have (repeatedly) been assessed around the globe (e.g. Bauer, Durant, \& Evans, 1994; Bauer, Shukla, \& Allum, 2012; Miller, 2004; Pardo \& Calvo, 2002, 2004). ${ }^{4}$ The primary interest of these studies was, and often still is, to determine people's scientific literacy, their favorableness towards S\&T, and its public funding; often, data are compared across time and countries (Besley, 2013). Although only few data exist for South Africa, initial findings highlight the diversity of public perceptions of S\&T in this country: There is a mixture of promises and reservations of S\&T, with-predominantly-scientific literacy, age, and education affecting these attitudes (Guenther \& Weingart, 2016; Reddy, Gastrow, Juan, \& Roberts, 2013).

Many investigations into public perceptions of S\&T, mostly in the form of quantitative surveys, assume that a combination of interest in and knowledge of science shape attitudes towards science and, in turn, support for its public funding (Besley, 2013). While the Eurobarometer (e.g. European Commission, 2013) or the United States National Science Foundation "Science Indicators" (NSF, 2016) studies usually summarize descriptive findings, academic research has given much attention to the correlation between knowledge and attitudes (Allum, Sturgis, Tabourazi, \& Brunton-Smith, 2008; Bauer, Allum, \& Miller, 2007; Sturgis \& Allum, 2004). ${ }^{5}$

Surveys used to assess public perceptions of S\&T have frequently been criticized. This criticism is particularly related to the operationalization of relevant constructs (e.g. Muñoz, Moreno, \& Luján, 2012; Sturgis \& Allum, 2004), underlying models of science communication (e.g. Bauer et al., 2007), and the lack of a clear theoretical model of public perceptions of S\&T (e.g. Besley, 2013). The main critique regarding attitudinal items is that they combine different sub-constructs, some more specific than others (Pardo \& Calvo, 2004). The items never clearly indicate what respondents think about when asked to express attitudes towards science (see also Allum et al., 2008; Kallerud \& Ramberg, 2002; Muñoz et al., 2012; Wynne, 1991), if respondents have such attitudes at all. Questions to measure scientific literacy often ask for textbook knowledge (Allum et al., 2008), but it is questionable if people need this knowledge in their everyday lives (Gauchat, 2011; Wynne, 1995). Surveys often exclude cultural (Pardo \& Calvo, 2002, 2004) or social contexts (Gauchat, 2011, 2012). Only a few researchers have tried to link the analysis of attitudes towards science to culture, 
values, and social settings, let alone to the everyday context of the people whose attitudes are analyzed (Pardo \& Calvo, 2006).

That is why new (research) directions have been called for. In segmentation studies, the assumption is that subgroups of a society share similar characteristics and possess distinct cultural perspectives (Gauchat, 2012; Schäfer et al., 2018). Such studies are a prerequisite to create effective messages "that are responsive to the concerns, needs, and perspectives of specific populations" (Slater, 1996, p. 267). There are different approaches among these studies (Cormick \& Malzoni Romanach, 2014; Schäfer et al., 2018; Slater, 1996); some of them acknowledge that groups of a society with different socio-demographic characteristics also differ with respect to their perceptions of science. For instance, Bauer (2012) shows how public perceptions of S\&T vary among different age cohorts (i.e. generational trends). Liu, Tang, and Bauer (2012) created a typology of five clusters of populations in China and Europe. In China, as a developing country, rural populations have a lower level of education, less knowledge of and interest in science, and are less engaged with science. Compared to urban groups, rural publics also hold more negative attitudes towards science. The authors highlight that income, level of education, and the urban-rural divide seem to be the most important determining factors of public perceptions of S\&T in China.

There are similar findings for South Africa. Guenther and Weingart (2018) found that on the one side there are literate and educated publics, who predominantly live in urban areas and use sources of scientific information more often. They see more promises and have fewer reservations towards S\&T. On the other side, there are publics who reside in rural areas, are less educated, have a lower level of literacy, and they see fewer benefits and have more reservations towards S\&T. Not surprisingly, rural publics have less income and use sources of scientific information less often; they may also have less access to them. For some rural publics, it seemed to be difficult to express attitudes towards S\&T at all (Guenther \& Weingart, 2018; for Europe, see Pardo \& Calvo, 2006).

Extending what we know from survey research, qualitative studies have the potential to throw light on the role of local and social contexts (Michael, 2002; Putsche, Hormel, Mihelich, \& Storrs, 2017; Wynne, 1995; see also Muñoz et al., 2012); however, there are only a few studies that come close to meet this challenge (e.g. Michael, 1992; Wynne, 1992). Sometimes quantitative surveys contain qualitative parts (e.g. Miller, 2004) or are accompanied by qualitative studies (e.g. Market \& Opinion Research International [MORI], 2005; Office of Science and Technology [OST] \& Wellcome Trust, 2000).

Qualitative research shows, not surprisingly, that science "means different things to different people in different situations" (Wynne, 1991, p. 112). People often define science using examples from school education, while they seem to be less aware of the importance of science in their daily life (MORI, 2005; OST \& Wellcome Trust, 2000). Only a small number of people were able to provide a (scientifically) acceptable explanation of what it means to study something scientifically or to explain what an experiment is (Miller, 2004). Findings also show that science, to be perceived as interesting and important to people, has to be of high direct relevance and/or utility to them (Wynne, 1991, 1995), such as health issues and specific technologies (MORI, 2005), i.e. it has to be related to people's personal, local contexts, and experiences (Irwin \& Michael, 2003; Kallerud \& Ramberg, 2002). If people feel that scientists lack an understanding of local contexts-as in the case of some governmental regulations that are informed by science-this can even result in distrust in science (Putsche et al., 2017).

Qualitative studies, although appropriate to assess how people understand science in their everyday life contexts, can also be criticized; for instance regarding small sample sizes, the specific conditions and research questions (RQs) that they answer, and the low level of generalization the findings have. In the present study, the concept of cultural distance is used as a theoretical framework to better describe the role of specific local settings in shaping perceptions of science. This will then translate into a study making use of qualitative and quantitative elements of the public perceptions of science literature. 


\section{The cultural distance to science}

Raza et al. (2009) offer a theoretical framework with their notion of cultural distance in which perceptions of science are thoughtfully integrated. Cultural distance ${ }^{6}$ exists between science (i.e. scientific knowledge) and people's cultural thought complexes. The authors describe this as the natural divide between science and people's worldviews (i.e. their cultural locale) (Raza \& Singh, 2012). Several factors define how culturally distant the scientific knowledge system might be from people's worldviews: on the part of science, distance results from the complexity of its methods and language, while on the side of people's everyday experiences and worldviews, social and economic concerns as well as educational background and cultural positions may be influential (see Raza, Singh, \& Dutt, 2002). Hence, based on these criteria, any representative sample is composed of so-called publics who exhibit a larger or smaller cultural distance to science. Although the authors-in empirical investigations-only focus on the question how education influences the cultural distance to science (Raza et al., 2009; Raza \& Singh, 2012), theoretically they highlight that the cultural distance is determined by economic conditions, literacy levels, access to media, age, cultural and religious predispositions, and geographical locations. The idea that these factors, taken together, constitute different publics with various distances to science is in line with the approach of segmentation studies that assume that these factors shape perceptions of science. Both approaches acknowledge that there are unique publics (identified by defined characteristics). We assume that these publics might then form different perceptions of science that at the same time represent various distances to science (Guenther \& Weingart, 2018).

For some publics, perceptions include neither any experience with nor any knowledge about science; opinions are formed and conclusions are drawn based on extra-scientific knowledge, such as cultural or religious explanations (Raza $\&$ Singh, 2012). For others, perceptions entail very specific experiences, such as science education in school, the proximity of a research lab, or exposure to science news on television (TV). Hence, we propose that no or vague perception(s) of science would mean there is a large cultural distance, while more sophisticated and knowledgeable perceptions of science indicate a smaller cultural distance to science (see also Raza et al., 2002, 2009).

Applying this to initial findings from South Africa, one would assume that rural publics exhibit the greatest distance to science, when compared to publics who live in urban areas, where a higher level of education and media exposure prevails (Guenther \& Weingart, 2018). If science communication is to reach these publics effectively, it has to be designed with consideration of their specific contexts. Analyzing publics in their local and social settings might be best achieved when integrating what we know from segmentation studies into a study combining qualitative and quantitative elements.

\section{The current study}

To understand better how rural South Africans perceive science in a daily context, the present exploratory study focuses on the local and social context of people (e.g. Michael, 2002). In line with findings from segmentation studies and theoretical notions on cultural distance, this article refers to different rural publics.

The first RQ wants to assess the cultural distance to science of rural South African publics (Guenther \& Weingart, 2018) in more detail.

RQ1: How culturally distant to science are rural South African publics?

Apart from studying the cultural distance to science of rural publics in general, the existence of the two big astronomical installations in Sutherland and Carnarvon makes it possible to study their specific effect on how people perceive and understand science in the context of their daily life. One assumption is that in these towns, through experience, people may perceive a smaller distance to science than people living in towns with no connection to any science. The reason for this assumption is that local contexts are supposed to shape people's worldviews (e.g. Raza et al., 2009) and local 
experiences also affect perceptions of science (Michael, 2002; Putsche et al., 2017; Wynne, 1995). The second RQ is:

RQ2: Is the cultural distance to science of rural South African publics different between towns with no connection to science and towns hosting large scientific installations?

\section{Method}

\section{Study design and participants}

To answer the RQs, semi-structured, in-depth interviews in four rural South African towns (13 in each town) were conducted from August-October 2016. The interviews were done in person by the article's authors, at interviewees' offices, homes, or in public spaces, using an interview guide, either in Afrikaans $(n=39 ; 74 \%)$ or English $(n=13 ; 26 \%)$ language.

The semi-structured format allowed follow-up questions based on responses. Hence, the interviewee determined each interview's length. Most of the interviews lasted less than half an hour $(M=27.19$; $\mathrm{SD}=10.59)$. Interviews were tape recorded with participant consent and fully transcribed verbatim (and where necessary translated into English) afterwards. Data extracts were anonymized to protect participant confidentiality.

The towns chosen for this study were, as mentioned above, Clanwilliam, Paternoster, Sutherland, and Carnarvon. Table 1 provides an overview of the towns.

In order to achieve similar (though not representative) samples of a variety of people in each town that differ according to the criteria mentioned in the cultural distance literature (e.g. economic conditions, age, gender), interviewees were found based on different approaches. We pre-arranged interviews with teachers, farmers, people employed by regional government institutions, and business owners for three reasons: these people were easily identifiable via the Internet, it usually requires an appointment to interview them, and we believed they might be helpful in identifying further potential interviewees. Once we arrived in the towns, we used the above-mentioned persons for snowballing, but we also approached people on the street and at their work place, arranging interview appointments. Table 2 provides an overview of socio-demographic information of interviewees in each town.

Table 1. Overview of the towns.

\begin{tabular}{|c|c|c|c|c|}
\hline Stats & Clanwilliam & Paternoster & Sutherland & Carnarvon \\
\hline Province & Western Cape & Western Cape & Northern Cape & Northern Cape \\
\hline Population & 7674 & 1971 & 2836 & 6612 \\
\hline \multicolumn{5}{|c|}{ All towns count as small rural towns (inhabitant numbers $<8000$ ) } \\
\hline \multirow{3}{*}{$\begin{array}{l}\text { Main population } \\
\text { groups }\end{array}$} & Coloureds ${ }^{\mathrm{a}}: 69 \%$ & Coloureds: $72 \%$ & Coloureds: $78 \%$ & Coloureds: $87 \%$ \\
\hline & Black: $23 \%$ & Black: $16 \%$ & White: $13 \%$ & White: $8 \%$ \\
\hline & White: $8 \%$ & White: $12 \%$ & Black: $8 \%$ & Black: $5 \%$ \\
\hline \multirow[t]{3}{*}{ First language } & Afrikaans: $78 \%$ & Afrikaans: $83 \%$ & Afrikaans: $96 \%$ & Afrikaans: 96\% \\
\hline & Sotho: $9 \%$ & isiXhosa: 9\% & English: 2\% & English: 2\% \\
\hline & isiXhosa: $8 \%$ & English: 6\% & Others: $2 \%$ & Others: $2 \%$ \\
\hline
\end{tabular}

Towns show similar make-up and have similar social problems (unemployment, alcohol and drug abuse, teenage pregnancy, and crime)

\begin{tabular}{|c|c|c|c|c|}
\hline Main industry & $\begin{array}{l}\text { Farming (including } \\
\text { Rooibos tea) }\end{array}$ & Fishing (e.g. crayfish) & Farming & Farming \\
\hline $\begin{array}{l}\text { Scientific } \\
\text { installation }\end{array}$ & None & None & SALT & SKA \\
\hline Conclusion & $\begin{array}{l}\text { Agricultural town without } \\
\text { connection to science }\end{array}$ & $\begin{array}{l}\text { Fishing town without } \\
\text { connection to science }\end{array}$ & $\begin{array}{l}\text { Agricultural town with } \\
\text { connection to science }\end{array}$ & $\begin{array}{l}\text { Agricultural town with } \\
\text { connection to science }\end{array}$ \\
\hline
\end{tabular}

Notes: Numbers base on a Census in 2011.

${ }^{a}$ Coloureds is a term used in South Africa to describe descendants of mixed ethnic heritage. 
Table 2. Socio-demographic overview (n (percent)).

\begin{tabular}{|c|c|c|c|c|c|}
\hline \multirow[b]{2}{*}{ Socio-demographics } & \multicolumn{4}{|c|}{ Towns } & \multirow[b]{2}{*}{ Total } \\
\hline & Clanwilliam & Paternoster & Sutherland & Carnarvon & \\
\hline \multicolumn{6}{|l|}{ Population group } \\
\hline Black & $1(1.9)$ & $1(1.9)$ & - & $1(1.9)$ & $3(5.8)$ \\
\hline Coloured & $4(7.7)$ & $6(11.5)$ & $9(17.3)$ & $8(15.4)$ & $27(51.9)$ \\
\hline White & $8(15.4)$ & $6(11.5)$ & $4(7.7)$ & $4(7.7)$ & $22(42.3)$ \\
\hline \multicolumn{6}{|l|}{ Gender } \\
\hline Male & $7(13.5)$ & $7(13.5)$ & $9(17.3)$ & $7(13.5)$ & $30(57.7)$ \\
\hline Female & $6(11.5)$ & $6(11.5)$ & $4(7.7)$ & $6(11.5)$ & $22(42.3)$ \\
\hline \multicolumn{6}{|c|}{ Age $(M=45.88 ; S D=14.99 ;$ here years in categories) } \\
\hline$<30$ & $2(3.8)$ & $3(5.8)$ & $3(5.8)$ & $3(5.8)$ & $11(21.2)$ \\
\hline $30-39$ & $1(1.9)$ & $1(1.9)$ & $3(5.8)$ & $3(5.8)$ & 8 (15.4) \\
\hline $40-49$ & $4(7.7)$ & $3(5.8)$ & $2(3.8)$ & $2(3.8)$ & $11(21.2)$ \\
\hline $50-59$ & $5(9.6)$ & $4(7.7)$ & $2(3.8)$ & $2(3.8)$ & $13(25.0)$ \\
\hline$>60$ & $1(1.9)$ & $2(3.8)$ & $3(5.8)$ & $3(5.8)$ & $9(17.3)$ \\
\hline \multicolumn{6}{|l|}{ Education } \\
\hline Low & $3(5.8)$ & - & $3(5.8)$ & $1(1.9)$ & $7(13.5)$ \\
\hline Moderate & $5(9.6)$ & $8(15.4)$ & $7(13.5)$ & $5(9.6)$ & $25(48.1)$ \\
\hline High & $3(5.8)$ & $5(9.6)$ & $3(5.8)$ & $7(13.5)$ & $20(38.5)$ \\
\hline \multicolumn{6}{|l|}{ Home language } \\
\hline Afrikaans & $12(23.1)$ & $10(19.2)$ & $12(23.1)$ & $12(23.1)$ & $46(88.5)$ \\
\hline English & - & $2(3.8)$ & $1(1.9)$ & - & $3(5.8)$ \\
\hline Other & $1(1.9)$ & $1(1.9)$ & - & $1(1.9)$ & $1(1.9)$ \\
\hline \multicolumn{6}{|l|}{ Occupational level } \\
\hline Low & $5(9.6)$ & $8(15.4)$ & $8(15.4)$ & $5(9.6)$ & $26(50.0)$ \\
\hline Moderate & $4(7.7)$ & $5(9.6)$ & $3(5.8)$ & $4(7.7)$ & $16(30.8)$ \\
\hline High & $4(7.7)$ & - & $2(3.8)$ & $4(7.7)$ & $10(19.2)$ \\
\hline \multicolumn{6}{|l|}{ Income } \\
\hline$<\mathrm{R} 3000$ & $2(4.1)$ & $1(2.0)$ & $6(12.2)$ & $2(4.1)$ & $11(21.2)$ \\
\hline R $3000-7500$ & $2(4.1)$ & $5(10.2)$ & $3(6.1)$ & $2(4.1)$ & $12(23.1)$ \\
\hline R $7500-15000$ & $1(2.0)$ & $5(10.2)$ & $1(2.0)$ & $2(4.1)$ & $9(17.3)$ \\
\hline R $15000-30000$ & $4(8.2)$ & - & $1(2.0)$ & $4(8.2)$ & $9(17.3)$ \\
\hline$>$ > 30000 & $3(6.1)$ & $1(2.0)$ & $1(2.0)$ & $3(6.1)$ & $8(15.4)$ \\
\hline \multicolumn{6}{|c|}{ Attendance of religious services } \\
\hline No religion & - & $3(6.7)$ & - & $3(6.7)$ & $6(11.5)$ \\
\hline$<$ Once a week & $4(8.9)$ & $4(8.9)$ & $6(13.3)$ & $3(6.7)$ & $17(32.7)$ \\
\hline Once a week & $4(8.9)$ & $3(6.7)$ & $1(2.2)$ & $2(4.4)$ & $10(19.2)$ \\
\hline >Once a week & $4(8.9)$ & $2(4.4)$ & $4(8.9)$ & $2(4.4)$ & $12(23.1)$ \\
\hline
\end{tabular}

Notes: Running Fisher's exact test, there were no significant differences between the towns. Low education $=$ no schooling or primary school; moderate education = high school until matric; high education = tertiary education. Low occupation =cleaners, waiters, caregiver, farm worker; moderate occupation =chefs, small business owner, secretaries; high occupation = teachers, farm owners, business owners.

\section{Interview guide}

The interview guide was semi-structured, with a combination of open-ended and closed questions. The guide was informed by both quantitative and qualitative research studies. Prior to conducting the interviews, the interview guide was pretested with six interviewees and adjusted appropriately. The interview started by asking participants to elaborate on what it is like to live in the respective community. This very general opening question was supposed to make interviewees feel comfortable.

Interest in science was assessed by asking interviewees to rank several fields of interest: politics, sports, science, religion, economy and finances, arts, and culture (see European Commission, 2013). Exposure to science was assessed by asking interviewees if they visited any of the following in the last 12 months: museum, science center, planetarium, zoo or aquarium, nature reserve, public library, and research site (Liu et al., 2012). Both interest in and exposure to science were informed by quantitative research. Experience with scientists, asking participants if they were aware of any situation in which they had spoken to a scientist, and if not, if they had ever seen a scientist, was included as a qualitative measure of the personal distance to science. For the individual definition of science, to 
assess what respondents think of science, we prepared cards with scientific terms and asked interviewees to describe what they associate with these: discovery, invention, research, experiment, university, professor, proof, and science (extended approach of OST \& Wellcome Trust 2000; Miller, 2004). This question was specifically designed to overcome some of the criticism regarding survey research. We further wanted to know if participants can name examples of science, and-to see science in their local, daily life context (MORI, 2005) - we asked if they are aware of any examples where science has helped to solve problems in their community, or where science needs to address problems in their community. We also wanted to know what interviewees think science can do for them and for their families, to assess personal expectations of science. Furthermore, we included their evaluation of public funding of science (Besley, 2013; Miller, 2004), creating a unique case in which participants should imagine the government had money available. We asked them to tell us if this money should be spent on science and, if yes, on which scientific field. Lastly, we asked participants if they would support a tax increase so that more money could be available for the specific field they mentioned before.

Relevant information about the interviewees that we assessed, next to the ones provided in Table 2, were primary source of scientific information (categorized as new media: 33\%, traditional media: $46 \%$, educational leaders: $8 \%$, books: $10 \%$ ), and a variable assessing if interviewees have ever lived in an urban area $(48 \%)$ or not $(52 \%)$. The variables were drawn from the cultural distance literature (Raza et al., 2009).

\section{Qualitative content analysis}

A qualitative content analysis, performed in ATLAS.ti, was used to analyze interview transcripts. Two coders applied an integrated approach to develop a code structure: a deductive (fixed categories based on theory or previous studies) and an inductive (codes emerging from the data) approach. After coding training, each coder coded half of the interview transcripts; transcripts were then reanalyzed by the respective other coder, to increase validity and reliability of coding.

For interest in science, it was coded if interviewees had high, moderate, or low interest. Subsequently, for exposure to science, we coded high exposure, moderate exposure, and low exposure. For experience with scientists, we coded if interviewees had direct (spoken to a scientist), indirect (seen a scientist), or no experience. For the individual definitions of scientific words, we coded if interviewees explained them in a scientific way, in a personal way, or did not explain them at all. For the questions referring to examples of science, we coded if interviewees were or were not aware of any examples. For expectations of science, we coded if they had expectations, or not. Public funding and tax increase were coded as an evaluation: positive, negative, or not existent.

For all codes, we also elucidated the specific examples interviewees used to explain or justify their responses.

\section{Data analysis}

A first step towards analyzing the data and answering RQ1 was to identify different rural publics. A multiple correspondence analysis (MCA) using Homals' procedure was performed in SPSS. In line with notions on cultural distance, the variables listed in Table 2, i.e. the sociodemographic information, were entered into the MCA. Based on discrimination measures, age and gender were excluded from the analysis. Figure 1 displays the MCA's outcome. Based on the proximity of variables, three different publics were identified. Next, we compared codes in ATLAS.ti for each public in each town of our sample separately, working towards answering the RQs. In particular, the query tool in ATLAS.ti was used to retrieve coded content and good quotations. 


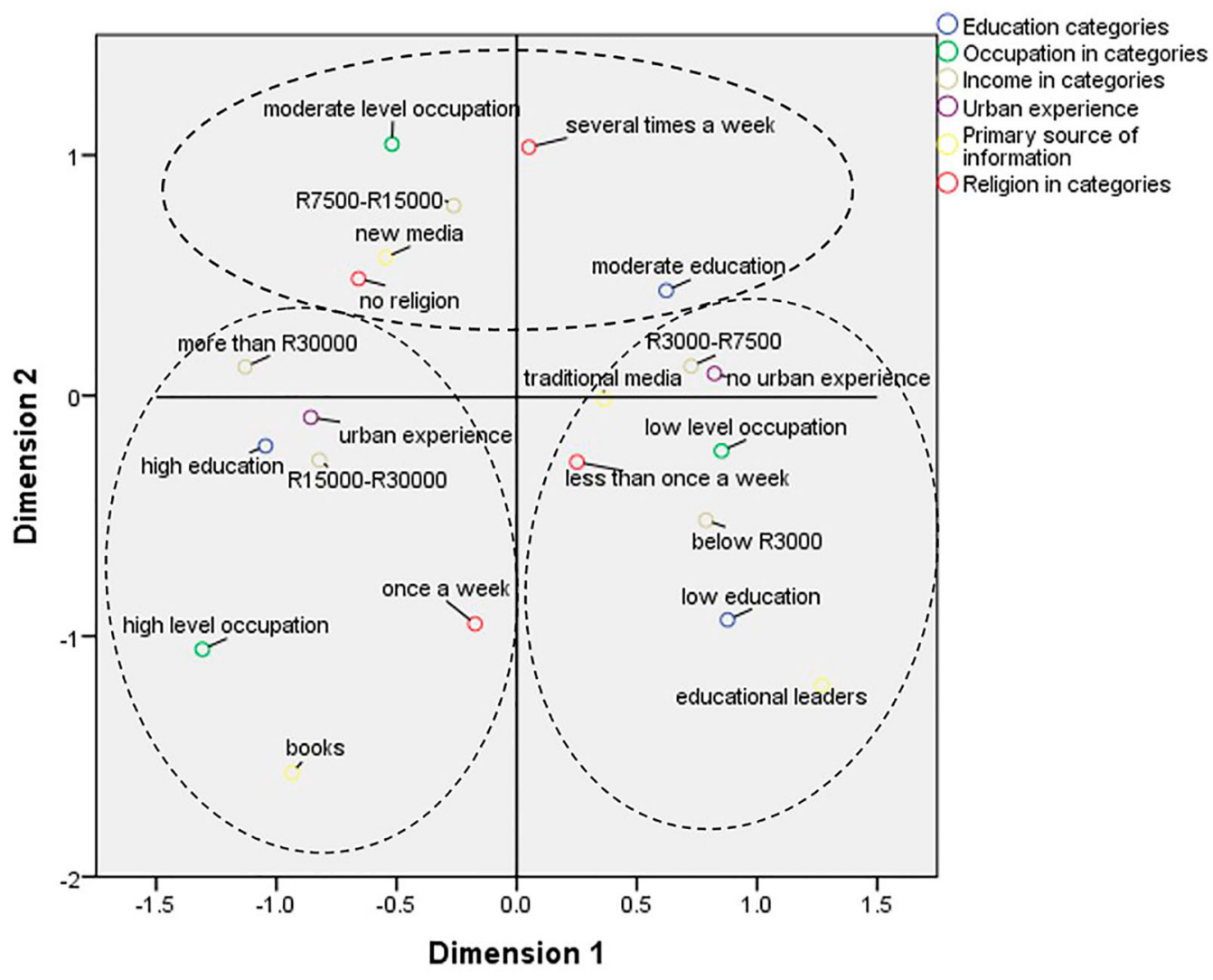

Figure 1. MCA (Homals procedure) to identify publics.

\section{Results}

The publics will be introduced first (see Figure 1), before the RQs will be answered for the four towns (see summary in Table 3). From Figure 1, formal education and urban experience seemed to be the strongest separating characteristic between the publics.

Public 1: "Culturally close to science" ( $n=15 ; 29 \%)$. Interviewees grouped together in this public shared a high level of formal education, a high-level occupation, urban experience, and a comparatively high income. They also more often tended to use books as a primary source of scientific information, and many of them were regular churchgoers.

Compared to the other publics, this one had the most interest in science and the highest amount of exposure to it, equally in all four towns. This public also stated the highest amount of direct experiences with scientists. Interviewees in Clanwilliam made a connection to the local rooibos industry: "We have rooibos in the town, so we have scientists in the town. They make the tea and tea products", said a teacher at the local high school. Farmers in Clanwilliam also stated to have regular interaction with scientists. One of them said:

Our whole business is science-based. You know, if you work with livestock or work with the citrus. We have citrus, we have stone fruits, and there is rooibos tea. [...] And you use science everywhere. [...] It is consultants that we use.

An estate agent in Paternoster remembered being to a scientific presentation, in which she met the woman who is supposed to go to Mars. In Carnarvon and Sutherland, interviewees predominantly had direct experience through the installations. They either had spoken to people at the observatory in Sutherland or had met a number of the scientists that work for SKA. 
Table 3. Perceptions of science among rural publics (with comparison of towns).

\begin{tabular}{|c|c|c|c|}
\hline $\begin{array}{l}\text { Categories (cultural } \\
\text { distance to science) }\end{array}$ & $\begin{array}{l}\text { Public 1: "Culturally close to } \\
\text { science" }\end{array}$ & $\begin{array}{l}\text { Public 2: "Moderately close to } \\
\text { science" }\end{array}$ & $\begin{array}{l}\text { Public 3: "Culturally distant to } \\
\text { science" }\end{array}$ \\
\hline Interest in science & High interest (in all four towns) & $\begin{array}{l}\text { Moderate interest (higher in } \\
\text { Sutherland) }\end{array}$ & Low interest (in all four towns) \\
\hline Exposure to science & High exposure (in all four towns) & $\begin{array}{l}\text { Moderate exposure (in all four } \\
\text { towns) }\end{array}$ & $\begin{array}{l}\text { Low exposure (in all four } \\
\text { towns) }\end{array}$ \\
\hline $\begin{array}{l}\text { Experience with } \\
\text { scientists }\end{array}$ & $\begin{array}{l}\text { Direct experience (in all four } \\
\text { towns, in Carnarvon and } \\
\text { Sutherland related to } L S I \text { ) }\end{array}$ & $\begin{array}{l}\text { Indirect experience (in Carnarvon } \\
\text { sometimes and in Sutherland } \\
\text { particularly related to } L S I \text { ) }\end{array}$ & $\begin{array}{l}\text { No experience (one exception } \\
\text { in Sutherland) }\end{array}$ \\
\hline f science & $\begin{array}{l}\text { Mostly scientific explanations (in } \\
\text { all four towns) }\end{array}$ & $\begin{array}{l}\text { Mostly personal explanations (in } \\
\text { Sutherland more scientific and } \\
\text { related to } L S I \text { ) }\end{array}$ & $\begin{array}{l}\text { Mostly no explanation (in } \\
\text { Sutherland more scientific } \\
\text { and related to } L S I \text { ) }\end{array}$ \\
\hline Examples & $\begin{array}{l}\text { Awareness of examples (in } \\
\text { Carnarvon and Sutherland } \\
\text { related to } L S I \text { ) }\end{array}$ & $\begin{array}{l}\text { Awareness of examples (in } \\
\text { Sutherland reference to } L S I \text { ) }\end{array}$ & $\begin{array}{l}\text { Little awareness of examples } \\
\text { (in Sutherland sometimes } \\
\text { reference to } L S I \text { ) }\end{array}$ \\
\hline $\begin{array}{l}\text { Examples of problems } \\
\text { science helped } \\
\text { solving }\end{array}$ & $\begin{array}{l}\text { Awareness of examples (in } \\
\text { Carnarvon and Sutherland } \\
\text { related to } L S I \text { ) }\end{array}$ & $\begin{array}{l}\text { Less awareness of examples (except } \\
\text { in Sutherland, with reference to } \\
\text { LSI) }\end{array}$ & $\begin{array}{l}\text { Little or no awareness of } \\
\text { examples (in all four towns) }\end{array}$ \\
\hline $\begin{array}{l}\text { Examples of problems } \\
\text { science should } \\
\text { address }\end{array}$ & $\begin{array}{l}\text { Awareness of examples (in all } \\
\text { four towns) }\end{array}$ & $\begin{array}{l}\text { Awareness of examples (in } \\
\text { Sutherland examples related to } \\
L S I \text { ) }\end{array}$ & $\begin{array}{l}\text { Little or no awareness of } \\
\text { examples (in all four towns) }\end{array}$ \\
\hline Expectations & $\begin{array}{l}\text { Many expectations (in all four } \\
\text { towns) }\end{array}$ & $\begin{array}{l}\text { Many expectations (in LSI-towns } \\
\text { related to job creation) }\end{array}$ & $\begin{array}{l}\text { Little or no expectations (in all } \\
\text { four towns) }\end{array}$ \\
\hline Public funding & Positive (in all four towns) & $\begin{array}{l}\text { Positive (more reservations in } \\
\text { Carnarvon, more astronomy- } \\
\text { related in Sutherland) }\end{array}$ & Positive (in all four towns) \\
\hline Tax increase & $\begin{array}{l}\text { Equal number for or against } \\
\text { support (in Carnarvon and } \\
\text { Sutherland more support) }\end{array}$ & $\begin{array}{l}\text { Equal number for or against } \\
\text { support (but more positive in } \\
\text { Sutherland) }\end{array}$ & all four towns) \\
\hline
\end{tabular}

Note: $\mathrm{LSI}=$ large scientific installations (SKA and SALT).

Compared to the other publics, interviewees in this one provided answers that indicated knowledge of science when it came to the individual definitions of science. Interviewees in Sutherland or Carnarvon sometimes referred to the large scientific installation in town. When asked for examples of science that they were aware of, interviewees in all towns mentioned cases from health, farming/ agriculture, technologies, and natural sciences; interviewees in Sutherland and Carnarvon, again, often cited work done by SALT and SKA. These differences between the towns prevailed when interviewees were asked for problems science had helped to solve in the community. Especially interviewees in Clanwilliam thought of environmental, farming, and water issues. "I see it in our citrus industry. [...] We deliver more than double the production that the previous generation thought was good production." A teacher also highlighted: "They are going to build the new damn, which will really help people in the community. It also creates jobs and will give more water." While interviewees in Sutherland and Carnarvon mentioned water problems that had been solved, they were also aware of the impact the installations have on the community. A science teacher in Sutherland explained that SALT did very much for the schoolchildren in providing materials and taking them to visit the observatory. A vice principal in Carnarvon added:

And with these social problems, I am talking about unemployment and with these, SKA science projects and things that, that they have brought, they then gave people employment.

When asked what problems science should address in the community, there were no real differences between the towns, with answers ranging from crime to water supply and poverty.

There were also no differences between the towns with respect to people's expectations of science. Interviewees predominantly maintained that science makes their life easier. A farmer in Carnarvon: "From something such as shoes that walk better or are healthier for your feet or a sun block that works, or a vehicle's tires that last longer." Health issues were also often stated; expectations related to job creation were mentioned third most often. A farm manager from Clanwilliam: 
I can quickly think of something like cancer. I mean, we have been busy with cancer for so long. If science can stop it, then it would be fantastic, for families that have cancer. If you look at AIDS, for our labor, and not just our labor, anyone that has AIDS, and if science can solve it, that would be fantastic.

Public funding of science was seen as something positive by interviewees; no one mentioned anything against it. There were no differences between the towns. Education and health were the primary fields to which funding money should be addressed.

An equal number of interviewees were either in favor of or opposed to supporting a tax increase to fund science; of all publics, this one showed the highest number of reservations. Interestingly, interviewees in Sutherland and Carnarvon were more favorably inclined towards a tax increase than interviewees in Clanwilliam and Paternoster. Those who were opposed to a tax increase felt that they already pay many taxes and rather favored a re-allocation of budgets. Nevertheless, based on their responses, people from this public showed the smallest cultural distance to science; thus, they were labeled "Culturally close to science."

Public 2: "Moderately close to science" $(n=21 ; 40 \%)$. This public is characterized by moderate levels of formal education and occupation, with an average income. Some of the interviewees had urban experience, while others did not. Interviewees in this group used new media as the primary source of information comparatively often.

Compared to the other publics, interviewees grouped to this public had a moderate exposure to science and moderate interest in this topic; however, interest was slightly higher among interviewees in Sutherland than in the other towns. In general, interviewees seemed to have mostly indirect experiences with scientists, with many of them living in Clanwilliam or Paternoster referring to scientists they saw in school or on TV. In contrast, some interviewees in Carnarvon referred to SKA, for instance, a taxi driver who takes schoolchildren to certain events organized by the research organization. In Sutherland, almost all interviewees referred to SALT. The school groundskeeper said: "There have been lots of people who come and give talks and things, whether it is math or science, or whatever."

When trying to explain the eight scientific terms, interviewees most often used personal explanations related to their everyday experiences. Almost all interviewees in Sutherland used SALT to explain the terms, and they tended to have associations that are more scientific. A tour guide, for instance, associated inventions with telescopes, professor with referring to astronomers, science in reference to astronomy, research with observing the skies, and discovery with a super nova in a nearby galaxy that was recently explored by scientists at SALT. A pensioner used a very similar approach, when he associated proof with how the telescope works. A business owner identified discovery stating: "Discovery, like Proxima Centauri, for me, it's amazing because people don't even know the word." A shop manager associated science with "the study of the space."

When asked for examples of science that interviewees were aware of, in all towns many examples were given from health, farming/agriculture, technologies, and natural sciences. However, while only one person in Carnarvon referred to SKA, again all interviewees in Sutherland mentioned SALT as an example of science. A pensioner, who referred to astronomy, recounted his impressions:

When you arrive at the observatory with the naked eye, and you see what, or you hear what is being done, they show you on their computer stuff. You then realize how little you know about all the discoveries they make, such as the new planets that are being discovered.

These differences between the towns prevailed when people were asked for problems science has helped to solve in the community. While interviewees in Clanwilliam and Paternoster-in general - gave fewer examples related to science (such as everyday-life technologies), interviewees in Carnarvon sometimes made a reference to SKA. A nurse explained that SKA is "sending our children to go and study. They get bursaries that are actually a plus for us as parents because many parents are poor." Again, awareness of the installation was much more prominent in Sutherland. The local tour guide: "We do have a computer center [...] that's actually equipped with 26 computers. That is basically open to general public and the whole of the town, where kids can come and do research." 
A similar picture emerged when asking interviewees about problems that science could address in the respective communities. In Clanwilliam, problems mentioned related to water supply and education. A small business owner said:

Water in Clanwilliam is a very big problem. [...], you started getting penalties if you use more than a certain amount of water in your house. I think that they can definitely do more.

In Paternoster, the local minister mentioned poaching of the fish and crayfish in particular as the main problem science should address. Again, only one person in Carnarvon, a nurse at the clinic, related her answer to the SKA. Other problems that the interviewees in Carnarvon mentioned relate to water supply and drug abuse. In Sutherland, the connection between problems the community faces and the large scientific installation was much more prominent. Problems were the same-education and poverty-but there was an expectation that the international research organization should address them. A tour guide explained:

What I would like to see is that, if we can get the scientists more involved, to motivate kids from a very young age. Because, you know, to go into the field of science you need to be good at math and science at school level.

Interviewees expected from science to ease their life, to make or keep them healthy, or to provide them with useful technology. For instance, a bookings manager in Paternoster:

I think science is, if applied correctly and what I've experienced in my daily life, is that it just makes everything that you use functional. Simple things that you didn't think about that you pick up and use like striking a match.

Only in Sutherland and Carnarvon did it occur to interviewees that science can actually create jobs.

Regarding public funding of science, there was-in general-support for it. Areas money should be directed to were water supply, medicine, desalination of seawater (Paternoster), and education. In Sutherland, almost all interviewees wanted to give additional money to astronomy. In contrast, in Carnarvon, two interviewees did not support public funding of science. As a shop owner stated: "there are so many other areas, where [money] is possibly needed more".

For three towns, the number was equal between those interviewees supporting a tax increase and those who did not. The exception was, again, Sutherland, where all interviewees supported a tax increase. In sum, people from this public showed a moderate cultural distance to science and this was used to label them as "Moderately close to science."

Public 3: "Culturally distant to science" ( $n=16 ; 31 \%)$. For interviewees in this public formal education, occupation and income were all low. Most interviewees never lived in an urban area, tended to have educational leaders and traditional media (radio, TV) as primary sources of scientific information comparatively often, and often went to church less than once a week.

Interviewees from this group, in general, had the least interest in science; they also had the least exposure to science, with no differences between the towns. Most interviewees had neither direct nor indirect experience with scientists; a small minority had indirect experience in the form of TV. An exception was a petrol attendant in Sutherland who had previously seen one of the scientists working for SALT.

These interviewees were the ones being the least able to come up with associations to any of the scientific terms, they had no real definitions of science. Noticeably, a librarian in Carnarvon used SKA to explain what a professor is, but this was the only example from this town. In Sutherland, SALT was more dominant in some of the answers, and led-in some cases-to more scientifically correct answers. The petrol attendant used SALT to explain research, a domestic worker used the observatory to explain discoveries. A farm worker stated:

Science is research technology, like the observatory, of course, it's a scientific place where they do research on the universe, certain stars, satellites, everything, the sun, the moon, when you want to find out something that you don't understand. 
Interviewees were less aware of examples of any science that they had heard of, and they were less likely to mention examples where science has helped solving problems in the community, or to mention problems that science can address in the future. Interviewees in Sutherland seemed to connect their general examples of science slightly more frequently to SALT.

Interviewees grouped to this public were the ones that could not express expectations from science. Only a few interviewees mentioned items such as having an easy life, being healthy, and sanitation, while most did not give an answer. There were no differences between the towns. Nevertheless, interviewees thought-without exception-that funding science is a good thing, and they showed the highest number supporting a tax increase. Education and health were mentioned as scientific fields, with no further differences between the towns. In sum, people from this public showed the largest cultural distance to science; thus, they were labeled accordingly.

\section{Discussion}

The findings showed that there are indeed different rural publics, but they are not automatically all culturally distant to science; rather, they exhibit various cultural distances to science (RQ1). Those that comparatively have a high level of education and have spent some time in urban environments ("Culturally close to science") display the smallest distance to science, but, somewhat surprisingly, they have the strongest reservations towards a tax increase for the benefit of science. In this small sample, we can see a finding corroborated in quantitative surveys elsewhere, namely that more knowledge of science does not necessarily result in more favorable attitudes towards science funding (see Allum et al., 2008). Those grouped together as moderately educated ("Moderately close to science") have average interest and exposure to science, largely indirect experiences, and they predominantly use associations for the terms relating to science that emerge from their immediate personal everyday experiences. They also showed a moderate awareness of examples of science and expressed some expectations from science. Thus, they took a middle position with respect to their cultural distance to science. In contrast, those interviewees grouped together as "Culturally distant to science" (low level of education and no urban experience) showed the greatest distance to science. They have less interest in science, have little or no exposure to it, no concrete experiences, and they do not formulate concrete expectations. However, this public expresses the strongest support for a tax increase in support of science.

Findings related to RQ1 are not surprising. The research literature points to the fact that people with higher formal education exhibit a smaller distance to science (Raza et al., 2009). Adopting findings of segmentation studies (Hine et al., 2014) to a study incorporating qualitative and quantitative elements of research nevertheless provided the possibility to analyze differences among publics in their local and social contexts in more detail. Assessing differences between the typical communities reveals interesting patterns in the sample of this study (RQ2). For those that were grouped as highly educated with urban experience ("Culturally close to science"), it did not really make a difference in what rural town they lived. Members of this public in all four towns had been exposed to science more directly and knew comparatively more about it than those of the other publics. The fact that interviewees in Sutherland and Carnarvon referred to the respective large scientific installations more often did not make a difference. Apparently, once people have lived in an urban environment, they are more directly exposed to science, be it through education and respective sources of information. Science is and remains an element in their everyday lives, even when they move (back) to a rural small-town context.

As the cultural distance to science increases for Publics 2 and 3, the differences in everyday contexts assume greater importance. Here, the installations in Sutherland and Carnarvon have a greater impact. However, their impacts are not identical. Especially interviewees in Sutherland showed more interest in and (indirect) experience with scientists than interviewees of the same public in Carnarvon. They also provided more correct assumptions about science and they alluded to the local installation (SALT) more frequently than their counterparts in Carnarvon did to SKA. Overall, 
interviewees in Sutherland showed a smaller cultural distance to science than interviewees in the other three towns. This even translates into their greater willingness to have a tax increase for the benefit of science. A similar, but weaker picture emerged in the third public, those that share a lower level of education and no urban experiences. In this case, interviewees from Sutherland showed the tendency to be slightly closer to science. The installations in the two towns make a difference to the perceptions of people who otherwise would not (or only moderately) come into contact with science. Thus, it can be assumed that the existence of a large scientific installation plays an important role as part of people's local contexts, having impact on perceptions and understandings of science.

Nevertheless, there remains a puzzling difference between members of the same publics in Carnarvon and Sutherland. There could be several reasons for this. SALT was established in 2005, while the dishes of SKA in Carnarvon are still in the process of being built. Hence, people in Sutherland benefited from SALT for a longer time. In addition, SALT is only a few miles out of town and-due to organized tours-has become a tourist attraction. Evening star gazing was turned into small businesses with accommodation in guesthouses attached; optical astronomy in its popular form is accessible and attractive to a broader public. The situation with SKA is different. The actual site is almost a hundred kilometers away from Carnarvon, and it is not open to the public, because of radio frequency interference and the fact that the dishes operate 24 hours a day. To add to this, radio astronomy is a much more remote and inaccessible field for the general public. Although the SKA consortium invests into education and science communication projects in town, few people seem to come into contact with it. Among those who do are local farmers, some of whom were affected by SKA's compulsory land purchases. Therefore, SKA is less present and less favorably so in the local and social contexts of people in Carnarvon than SALT in Sutherland.

The study has a number of notable limitations that translate into future research scenarios. The small sample size and the inclusion of four towns only do not allow any generalization of the findings. The central assumption of this paper, that a large scientific installation might have an impact on peoples' perceptions of science, should be tested again with a larger sample and controlling for more potential influencing factors. However, this might be seen as a common limitation of field studies. The sampling strategies that have been used in the present study could be improved as well, for instance using pre-defined quota plans to better represent a towns' population. In addition, more than four towns might be considered in future studies. The interview guide that was used in the present study was informed by both quantitative and qualitative research studies; it might be promising to use more open-ended questions in the future to more deeply analyze peoples' perceptions. It might also be a good suggestion not to just focus on rural publics, but to compare them to different (semi-)urban publics. Lastly, studies on how different segments of a society can best be reached by different types of communication are scarce (Hine et al., 2014); hence, it would be a promising approach to use the findings of the present study for designing communication strategies to reach rural publics more effectively. Subsequently, the findings might then even serve for sound future policy decisions.

\section{Notes}

1. Effective science communication is often defined as communication that informs (better) decision-making; however, this communication should begin by listening to audiences and identifying their needs, and it should relate to people's competences and interests (Fischhoff, 2013).

2. SALT is the largest optical telescope in the southern hemisphere and was built in 2005. SKA is a radio telescope project, which biggest part is being built in South Africa. While phase 1 of the SKA project starts to run in 2018, currently the first dishes (that form part of the MeerKAT project (initial construction started in 2009)) are already running. Both SALT and SKA are global projects, financed by several countries.

3. It is one of the set goals of segmentation studies to identify segments of a population, and then subsequently derive (science) communication strategies to better reach these segments, because "certain types of messages may be enthusiastically embraced by some members of the general public, but elicit indifference or outrage from others" (Hine et al., 2014, p. 441). 
4. For an overview of why research in this area was established, readers are guided to Besley (2013) and Allum et al. (2008). Research into public perceptions of S\&T, mostly in the form of quantitative surveys, is-in general-interested in the publics' scientific literacy; their interest, knowledge, and understanding of (the nature of) science; trust in science, scientists, and scientific institutions; media use; and attitudes towards science and its public funding (e.g. Bauer, 2012; Muñoz et al., 2012). Research in this field is interested in both general and specific public perceptions of S\&T (Allum et al., 2008).

5. The (contested) relationship between knowledge of science and attitudes towards science has led to frequent debates (Allum et al., 2008; Gauchat, 2011). Branded the deficit model, some researchers believed that if the public was more scientifically literate, they would be more favorable towards science (Sturgis \& Allum, 2004). Some researchers found support that higher literacy influences positive attitudes towards science (Allum, Sibley, Sturgis, \& Stoneman, 2014; Bauer et al., 1994; Sturgis \& Allum, 2004), which, in turn, positively influence support for its public funding (Muñoz et al., 2012). However, other researchers found only limited support for this connection, for instance regarding attitudes towards specific areas of scientific research (Allum et al., 2008), or in cross-cultural investigations (see Bauer et al., 1994; Bauer et al., 2007; Bauer, 2012).

6. Cultural distance is defined "as the distance that a worldview, attitude, perception, or an idea, generated within one cultural context, travels on a time scale for its democratization within the thought structure of the other cultural sub-group(s)" (Raza et al., 2009, p. 272).

7. The pretest was carried out with people from different communities in Stellenbosch, South Africa; hence, in a semi-rural context.

\section{Acknowledgements}

This work is based on research supported by the South African Research Chairs Initiative of the Department of Science and Technology (DST) and National Research Foundation (NRF) of South Africa. Any opinion, finding and conclusion or recommendation expressed in this material is that of the authors and the NRF does not accept any liability in this regard. The authors wish to thank their two anonymous reviewers for their good recommendations. We also want to thank Marina Joubert and Lauren Wildschut for reading the earlier drafts of this manuscript, and Harrie Esterhuyse for helping in conceptualizing this study.

\section{Disclosure statement}

No potential conflict of interest was reported by the authors.

\section{Funding}

This work was supported by National Research Foundation (93097).

\section{ORCID}

Lars Guenther (D) http://orcid.org/0000-0001-7760-0416

Peter Weingart (iD http://orcid.org/0000-0002-8275-525X

Corlia Meyer (D) http://orcid.org/0000-0002-2965-4054

\section{References}

Allum, N., Sibley, E., Sturgis, P., \& Stoneman, P. (2014). Religious beliefs, knowledge about science and attitudes towards medical genetics. Public Understanding of Science, 23(7), 833-849.

Allum, N., Sturgis, P., Tabourazi, D., \& Brunton-Smith, I. (2008). Science knowledge and attitudes across cultures: A meta-analysis. Public Understanding of Science, 17, 35-54.

Bauer, M. W. (2012). The changing culture of science across old Europe: 1989 to 2005. In M. W. Bauer, R. Shukla, \& N. Allum (Eds.), The culture of science. How the public relates to science across the globe (pp. 92-109). London: Routledge.

Bauer, M. W., Allum, N., \& Miller, S. (2007). What can we learn from 25 years of PUS survey research? Liberating and expanding the agenda. Public Understanding of Science, 16, 79-95.

Bauer, M. W., Durant, J., \& Evans, G. (1994). European public perceptions of science. International Journal of Public Opinion Research, 6(2), 163-186. 
Bauer, M. W., Shukla, R., \& Allum, N. (2012). Towards cultural indicators of science with global validity. In M. W. Bauer, R. Shukla, \& N. Allum (Eds.), The culture of science. How the public relates to science across the globe (pp. 1-17). London: Routledge.

Besley, J. C. (2013). The state of public opinion research on attitudes and understanding of science and technology. Bulletin of Science, Technology \& Society, 33(1/2), 12-20.

Cormick, C., \& Malzoni Romanach, L. (2014). Segmentation studies provide insights to better understanding attitudes towards science and technology. Trends in Biotechnology, 32(3), 114-116.

Department of Arts, Culture, Science and Technology. (1996). White paper on science and technology. Preparing for the 21st century. Pretoria: Government Printer.

Department of Science and Technology. (2014). Science engagement framework. Retrieved from http://www.pan.org. $\mathrm{za} /$ sites/default/files/publicationdocuments/2015031020SCIENCE20ENGAGEMENT\%20FRAMEWORK.pdf

European Commission. (2013). Responsible research and innovation (RII), science and technology (Special Eurobarometer 401). Retrieved from http://ec.europa.eu/public_opinion/archives/ebs/ebs_401_en.pdf

Fischhoff, B. (2013). The sciences of science communication. Proceedings of the National Academy of Sciences, 110(3), 14033-14039.

Gauchat, G. (2011). The cultural authority of science: Public trust and acceptance of organized science. Public Understanding of Science, 20(6), 751-770.

Gauchat, G. (2012). Politicization of science in the public sphere: A study of public trust in the United States, 1974 to 2010. American Sociological Review, 77(2), 167-187.

Guenther, L., \& Weingart, P. (2016). A unique fingerprint? Factors influencing attitudes towards science and technology in South Africa. South African Journal of Science, 112(7/8), 129-132.

Guenther, L., \& Weingart, P. (2018). Promises and reservations towards science and technology among South African publics: A culture-sensitive approach. Public Understanding of Science, 27(1), 47-58.

Hine, D. W., Reser, J. P., Morrison, M., Phillips, W. J., Nunn, P., \& Cooksey, R. (2014). Audience segmentation and climate change communication: Conceptual and methodological considerations. Wiley Interdisciplinary Reviews: Climate Change, 5, 441-459.

Irwin, A., \& Michael, M. (2003). Science, social theory and public knowledge. Maidenhead: Open University Press.

Kallerud, E., \& Ramberg, I. (2002). The order of discourse in surveys of public understanding of science. Public Understanding of Science, 11, 213-224.

Liu, X., Tang, S., \& Bauer, M. W. (2012). Comparing public understanding of science across China and Europe. In M. W. Bauer, R. Shukla, \& N. Allum (Eds.), The culture of science. How the public relates to science across the globe (pp. 139-157). London: Routledge.

Market \& Opinion Research International. (2005). Science in society. Findings from qualitative and quantitative research. Retrieved from https://www.ipsos-mori.com/Assets/Docs/Polls/Final_OSTreport_051110.PDF

Michael, M. (1992). Lay discourses of science: Science-in-general, science-in-particular, and self. Science, Technology, \& Human Values, 17(3), 313-333.

Michael, M. (2002). Comprehension, apprehension, prehension: Heterogeneity and the public understanding of science. Science, Technology, \& Human Values, 27(3), 357-378.

Miller, J. D. (2004). Public understanding of, and attitudes toward, scientific research: What we know and what we need to know. Public Understanding of Science, 13, 273-294.

Muñoz, A., Moreno, C., \& Luján, J. L. (2012). Who is willing to pay for science? On the relationship between public perception of science and the attitude to public funding of science. Public Understanding of Science, 21(2), $242-253$.

National Science Foundation. (2016). Science and engineering indicators 2016. Retrieved from https://www.nsf.gov/ statistics/2016/nsb20161/uploads/1/nsb20161.pdf

Office of Science and Technology, \& Wellcome Trust. (2000). Science and the public. A review of science communication and public attitudes towards science in Britain. Retrieved from https://wellcome.ac.uk/sites/default/files/ wtd003419_0.pdf

Pardo, R., \& Calvo, F. (2002). Attitudes toward science among the European public: A methodological analysis. Public Understanding of Science, 11, 155-195.

Pardo, R., \& Calvo, F. (2004). The cognitive dimension of public perceptions of science: Methodological issues. Public Understanding of Science, 13, 203-227.

Pardo, R., \& Calvo, F. (2006). Mapping perceptions of science in end-of-century Europe. Science Communication, 28 (1), 3-46.

Putsche, L., Hormel, L., Mihelich, J., \& Storrs, D. (2017). "You end up feeling like the rest of the world is kind of picking on you": Perceptions of regulatory science's threats to economic livelihoods and Idahoans' collective identity. Science Communication, 39(6), 687-712.

Raza, G., \& Singh, S. (2012). The cultures of public understanding of science - defining cultural distance. In M. W. Bauer, R. Shukla, \& N. Allum (Eds.), The culture of science. How the public relates to science across the globe (pp. 282-300). London: Routledge.

Raza, G., Singh, S., \& Dutt, B. (2002). Public, science, and cultural distance. Science Communication, 23(3), 293-309. 
Raza, G., Singh, S., \& Shukla, R. (2009). Relative cultural distance and public understanding of science. Science, Technology \& Society, 14(2), 269-287.

Reddy, V., Gastrow, M., Juan, A., \& Roberts, B. (2013). Public attitudes to science in South Africa. South African Journal of Science, 109(1/2), 1-8.

Schäfer, M. S., Füchslin, T., Metag, J., Kristiansen, S., \& Rauchfleisch, A. (2018). The different audiences of science communication: A segmentation analysis of the Swiss population's perceptions of science and their information and media use patterns. Public Understanding of Science, 10. doi:10.1177/0963662517752886

Slater, M. D. (1996). Theory and method in health audience segmentation. Journal of Health Communication, 1 , 267-284.

Sturgis, P., \& Allum, N. (2004). Science in society: Re-evaluating the deficit model of public attitudes. Public Understanding of Science, 13, 55-74.

The World Bank. (2015). Rural population South Africa (\% of total population). Retrieved from http://data.worldbank. org/indicator/SP.RUR.TOTL.ZS

Wynne, B. (1991). Knowledge in context. Science, Technology, \& Human Values, 16(1), 111-121.

Wynne, B. (1992). Misunderstood misunderstanding: Social identities and public uptake of science. Public Understanding of Science, 1, 281-304.

Wynne, B. (1995). Public understanding of science. In S. Jasanoff, G. E. Markle, J,C Peterson, \& T. Pinch (Eds.), Handbook of science and technology studies (pp. 361-388). Thousand Oaks, CA: Sage. 